\title{
Triindolylmethane-based high triplet energy glass-forming electroactive molecular materials
}

\author{
Mindaugas Kirkus ${ }^{a}$, Ramunas Lygaitis ${ }^{\text {a }}$, Ming-Han Tsai ${ }^{\text {b,c }}$, \\ Juozas V. Grazulevicius ${ }^{\mathrm{a}, *}$, Chung-Chih Wu ${ }^{\mathrm{b}, \mathrm{c}, * *}$ \\ ${ }^{a}$ Department of Organic Technology, Kaunas University of Technology, Radvilenu pl. 19, LT-50254 Kaunas, Lithuania \\ ${ }^{\mathrm{b}}$ Department of Electrical Engineering, Graduate Institute of Photonics and Optoelectronics, National Taiwan University, Taipei 106, Taiwan \\ ${ }^{\mathrm{c}}$ Department of Electrical Engineering, Graduate Institute of Electronics Engineering, National Taiwan University, Taipei 106, Taiwan
}

Received 1 October 2007; received in revised form 4 January 2008; accepted 16 January 2008

Available online 4 March 2008

\begin{abstract}
A series of new triindolylmethane-based compounds including those containing reactive functional groups were synthesized by the tandem addition-elimination-(Michael) addition reaction from $1 H$-indole and $1 H$-indole-3-carbaldehyde. The thermal, optical, photophysical and photoelectrical properties of the synthesized compounds were studied. The synthesized compounds exhibit moderate thermal stability with $5 \%$ weight loss temperatures ranging from 245 to $310^{\circ} \mathrm{C}$ and form glasses with glass transition temperatures in the range of $98-123{ }^{\circ} \mathrm{C}$. The ionization potentials of the synthesized compounds measured by the electron photoemission in air technique range from 5.67 to $5.80 \mathrm{eV}$. The solutions of the synthesized compounds show relatively high triplet energies in the range from 2.97 to $2.99 \mathrm{eV}$.
\end{abstract}

(C) 2008 Elsevier B.V. All rights reserved.

Keywords: Triindolylmethane; Molecular glass; High triplet energy; Ionization potential

\section{Introduction}

Since the first demonstration of efficient light emission from organic light emitting diodes (OLEDs) by the Kodak group [1], the foci of further research were on lower operating voltages, higher efficiencies and longer lifetimes of the devices. Over the past several years, organic electroluminescent devices have attracted growing interest for full-color flat-panel display applications because of their ability to emit colors throughout the visible spectrum and with high luminous efficiency [2]. The efficiency of light emission from fluorescent OLEDs is limited compared to OLEDs with phosphorescent (triplet) emitters. In a device without triplet emitters only the singlet excitons can recombine radiatively. Consequently, such a device has a maximal internal efficiency of $25 \%$. When triplet emitters are used in

\footnotetext{
* Corresponding author. Tel.: +88623366 3636; fax: +88622367 1909.

** Corresponding author at: Department of Electrical Engineering, Graduate Institute of Photonics and Optoelectronics, National Taiwan University, Taipei 106, Taiwan.

E-mail addresses: Juozas.Grazulevicius@ktu.lt (J.V. Grazulevicius), chungwu@cc.ee.ntu.edu.tw (C.-C. Wu).
}

a device, the maximal internal efficiency can be as high as $100 \%$ since the triplet emitters can harvest both singlet and triplet excitons [3]. The way to improve the efficiency of OLEDs is the use of an appropriate choice of phosphorescent dye dopants diluted in a host material with wide energy gap. Efficient electrophosphorescence can be generated by energy transfer from the host to the phosphorescent guest molecule. A good host material should possess three intrinsic criteria: (1) its triplet energy must be higher than that of the guest molecule to prevent backward energy transfer during operation $[2,4,5]$; (2) the conjugation in the host molecules must be extremely confined; (3) it must possess good morphological and chemical stabilities to extend the operational lifetime of the device.

Although 4,4'-bis(9-carbazolyl)-2,2'-biphenyl (CBP) has been commonly used as a host material in green and red phosphorescent devices, the triplet energy of CBP $(2.56 \mathrm{eV})$ is lower than those of the general blue triplet emitters $(>2.62 \mathrm{eV})$, resulting in an inefficient energy transfer from host to guest. Thus one of the major research efforts in phosphorescent OLEDs has been due to the development of host materials with large triplet energies with thermal stability. Currently, effective host materials reported for phosphorescent devices are limited within few 
structural features such as carbazole [6-8], dibenzofuran [9], phenylsilane [10] and fluorene [11] derivatives. In this paper we report on the synthesis and properties of new potential high triplet energy materials. We have chosen tri( $1 H$-indol-3yl)methane moiety as a major building block for the design and synthesis of the potential high triplet energy materials. In this moiety three indolyl fragments are connected at the C-3 position to the $\mathrm{sp}^{3}$ hybridized carbon atom which serves as a spacer to block $\pi$-conjugation. Some compounds reported in this article contain reactive oxiranyl and oxetanyl reactive functional groups. Such compounds could be of interest for the application of multilayer devices with (photo)cross-linked layers.

\section{Experimental}

\subsection{Materials}

The starting compounds, i.e. $1 H$-indole, $1 H$-indole-3-carbaldehyde, iodoethane, 1-iodobuthane, 2-(chloromethyl)oxirane, and 1-ethyl-4-iodobenzene were purchased from "Aldrich" and used as received. 3-(Bromomethyl)-3-methyloxethane (Chemada, Israel) was also used as received. All the required chemicals, i.e. potassium hydroxide, sodium sulphate, tetrabutylammonium hydrogen sulphate (TBAS), copper(I) iodide, trans-1,2-diaminocyclohexane, and concentrated hydrochloric acid were purchased from "Aldrich" and "Fluka". Organic solvents such as acetone, butan-2-one, toluene, 1,4-dioxane, methanol, and chloroform were purified and dried by standard methods [12].

Tri( $1 H$-indol-3-yl)methane (1): a mixture of $7.25 \mathrm{~g}$ $(0.05 \mathrm{~mol}) \quad 1 H$-indole, $\quad 11.71 \mathrm{~g} \quad(0.1 \mathrm{~mol}) \quad 1 H$-indole- $3-$ carbaldehyde, $1 \mathrm{ml}$ concentrated hydrochloric acid and $200 \mathrm{ml}$ methanol was heated at reflux for $3 \mathrm{~h}$ and then cooled to room temperature. The pale yellow solid was collected by filtration and washed with several portions of methanol and then recrystallized from toluene to afford the product as bright yellow crystals $\left(15 \mathrm{~g}, 83 \%\right.$ yield) $\mathrm{mp} 254-255^{\circ} \mathrm{C}$ (lit. $\left.254-256{ }^{\circ} \mathrm{C}[13]\right) . \mathrm{FW}=361.16 \mathrm{~g} \mathrm{~mol}^{-1}$. MS $\left(\mathrm{APCI}^{+}, 20 \mathrm{~V}\right)$, $m / z=362[\mathrm{M}+\mathrm{H}]^{+}$, 246. IR (in $\left.\mathrm{KBr}\right) v \mathrm{~cm}^{-1}: 3428,3403$ $(\mathrm{N}-\mathrm{H}), 3050\left(\mathrm{CH}_{\mathrm{ar}}\right), 1455\left(\mathrm{C}=\mathrm{C}_{\mathrm{ar}}\right), 1336(\mathrm{C}-\mathrm{N}) ; \gamma \mathrm{cm}^{-1}: 740$ $\left(\mathrm{CH}_{\mathrm{ar}}\right) .{ }^{1} \mathrm{H}$ NMR $\left(300 \mathrm{MHz}, \mathrm{DMSO}-d_{6}\right), \delta(\mathrm{ppm}): 6.11(\mathrm{~s}, 1 \mathrm{H}$, $\mathrm{CH}), 6.90\left(\mathrm{dd}, 3 H,{ }^{3} J_{\mathrm{HH}}=7.68,6.95 \mathrm{~Hz}, H-6\right), 6.99(\mathrm{~d}, 3 H$, $J=1.83 \mathrm{~Hz}, H-2), 7.05\left(\mathrm{dd}, 3 H,{ }^{3} J_{\mathrm{HH}}=8.05,6.95 \mathrm{~Hz}, H-5\right)$, 7.38 (d, $3 H, J=8.05 \mathrm{~Hz}, H-7), 7.45(\mathrm{~d}, 3 H, J=7.68 \mathrm{~Hz}, H-4)$, $10.76(\mathrm{~d}, 3 \mathrm{H}, J=1.83 \mathrm{~Hz}, \mathrm{~N} H)$. Anal. Calcd. for $\mathrm{C}_{25} \mathrm{H}_{19} \mathrm{~N}_{3}$ : C, 83.08; H, 5.30; N, 11.63. Found: C, 83.05; H, 5.26; N, 11.69 .

Tri(1-ethyl-1 $H$-indol-3-yl)methane $(2) .1 \mathrm{~g}(2.76 \mathrm{mmol})$ of $\operatorname{tri}(1 \mathrm{H}$-indol-3-yl)methane (1), $1.51 \mathrm{~g}(9.69 \mathrm{mmol})$ of iodoethane and $0.01 \mathrm{~g}(0.03 \mathrm{mmol})$ of TBAS were heated at reflux in $30 \mathrm{ml}$ of acetone and then $1.16 \mathrm{~g}(20.76 \mathrm{mmol})$ of powdered potassium hydroxide was added. After refluxing for $4 \mathrm{~h}$ the reaction mixture was cooled down to room temperature. The inorganic components were removed by filtration. The solvent was removed by distillation under reduced pressure and the residue was extracted with chloroform. The chloroform solution was washed with water, dried over $\mathrm{MgSO}_{4}$ and evaporated to dryness in vacuo. The crude product was purified by silica gel column chromatography using hexane/chloroform $(5: 1, \mathrm{v} / \mathrm{v})$ as an eluent. The product was obtained as pale yellow crystals ( $0.88 \mathrm{~g}, 71.5 \%$ yield) $\mathrm{mp}: 227-228^{\circ} \mathrm{C}$. $\mathrm{FW}=445.60 \mathrm{~g} \mathrm{~mol}^{-1}$. $\operatorname{MS}\left(\mathrm{APCI}^{+}, 20 \mathrm{~V}\right), m / z=446[\mathrm{M}+\mathrm{H}]^{+}, 302$. IR (in KBr) $v \mathrm{~cm}^{-1}$ : $3048\left(\mathrm{CH}_{\mathrm{ar}}\right), 2972\left(\mathrm{CH}_{\text {aliphatic }}\right), 1461\left(\mathrm{C}=\mathrm{C}_{\mathrm{ar}}\right), 1353(\mathrm{C}-\mathrm{N}) ; \gamma$ $\mathrm{cm}^{-1}: 732\left(\mathrm{CH}_{\mathrm{ar}}\right) .{ }^{1} \mathrm{H}$ NMR $\left(300 \mathrm{MHz}, \mathrm{CDCl}_{3}\right), \delta(\mathrm{ppm}): 1.41$ (t, $\left.9 H, J=6.95 \mathrm{~Hz},-\mathrm{CH}_{3}\right), 4.11\left(\mathrm{~m}, 6 \mathrm{H},-\mathrm{CH}_{2}-\right), 6.21(\mathrm{~s}, 1 \mathrm{H}$, $\mathrm{CH}$ ), $6.77(\mathrm{~s}, 3 H, H-2), 7.03\left(\mathrm{dd}, 3 H,{ }^{3} J_{\mathrm{HH}}=8.05,6.95 \mathrm{~Hz}\right.$, $H$-6), $7.24\left(\mathrm{dd}, 3 H,{ }^{3} J_{\mathrm{HH}}=7.68,7.32 \mathrm{~Hz}, H-5\right), 7.38(\mathrm{~d}, 3 H$, $J=8.05 \mathrm{~Hz}, H-7), 7.54$ (d, $3 H, J=8.05 \mathrm{~Hz}, H-4)$. Anal. Calcd. for $\mathrm{C}_{31} \mathrm{H}_{31} \mathrm{~N}_{3}$ : C, 83.56; H, 7.01; N, 9.43. Found: C, 83.52; H, $7.08 ; \mathrm{N}, 9.40$.

Tri(1-butyl-1H-indol-3-yl)methane (3) was synthesized by the similar procedure from $1 \mathrm{~g}(2.76 \mathrm{mmol})$ of tri $(1 \mathrm{H}$-indol3-yl)methane (1), $1.78 \mathrm{~g}(9.69 \mathrm{mmol})$ of 1-iodobutane, $1.16 \mathrm{~g}$ $(20.76 \mathrm{mmol})$ of powdered potassium hydroxide and $0.01 \mathrm{~g}$ $(0.03 \mathrm{mmol})$ of TBAS in acetone. The product was purified by silica gel column chromatography using hexane/ethyl acetate $(4: 1, \mathrm{v} / \mathrm{v})$ as an eluent. The product was obtained as pale yellow crystals $(1.15 \mathrm{~g}, 78.7 \%$ yield $) \mathrm{mp}: 226-227^{\circ} \mathrm{C}$. $\mathrm{FW}=529.76 \mathrm{~g} \mathrm{~mol}^{-1}$. MS $\left(\mathrm{APCI}^{+}, 20 \mathrm{~V}\right), m / z=530[\mathrm{M}+\mathrm{H}]^{+}$, 358. IR (in $\mathrm{KBr}) v \mathrm{~cm}^{-1}: 3048\left(\mathrm{CH}_{\mathrm{ar}}\right), 2870\left(\mathrm{CH}_{\text {aliphatic }}\right), 1461$ $\left(\mathrm{C}=\mathrm{C}_{\mathrm{ar}}\right), 1353(\mathrm{C}-\mathrm{N}) ; \gamma \mathrm{cm}^{-1}: 739\left(\mathrm{CH}_{\mathrm{ar}}\right) .{ }^{1} \mathrm{H} \mathrm{NMR}(300 \mathrm{MHz}$, $\left.\mathrm{CDCl}_{3}\right), \delta(\mathrm{ppm}): 0.92\left(\mathrm{t}, 9 \mathrm{H}, J=7,32 \mathrm{~Hz},-\mathrm{CH}_{3}\right), 1.31(\mathrm{~m}$, $6 \mathrm{H},-\mathrm{CH}_{2} \mathrm{CH}_{3}$ ), 1.77 (m, 6H, $\left.-\mathrm{CH}_{2} \mathrm{CH}_{2} \mathrm{CH}_{2}-\right), 4.04$ (t, $6 \mathrm{H}$, $\left.J=6.95 \mathrm{~Hz},-\mathrm{N}-\mathrm{CH}_{2}-\right), 6.19$ (s, $\left.1 H, \mathrm{CH}\right), 6.74$ (s, $3 H, H-2$ ), $7.01(\mathrm{dd}, 3 H, J=6.95,8.05 \mathrm{~Hz}, H-6), 7.21\left(\mathrm{dd}, 3 H,{ }^{3} J_{\mathrm{HH}}=6.95\right.$, $8.05 \mathrm{~Hz}, H-5), 7.36(\mathrm{~d}, 3 H, J=8.42 \mathrm{~Hz}, H-7), 7.52(\mathrm{~d}, 3 H$, $J=8.05 \mathrm{~Hz}, \mathrm{H}-4)$. Anal. Calcd. for $\mathrm{C}_{37} \mathrm{H}_{43} \mathrm{~N}_{3}: \mathrm{C}, 83.89 ; \mathrm{H}, 8.18$; N, 7.93. Found: C, 83.85; H, 8.14; N, 8.01.

Tri(1-(oxiran-2-ylmethyl)-1H-indol-3-yl)methane (4). $1 \mathrm{~g}$ (2.76 mmol) of tri( $1 H$-indol-3-yl)methane (1) was dissolved in $25 \mathrm{ml}$ of 2-(chloromethyl)oxirane. Then $1.16 \mathrm{~g}(20.76 \mathrm{mmol})$ of powdered potassium hydroxide and $0.53 \mathrm{~g}(3.77 \mathrm{mmol})$ of sodium sulphate were added in small portions. The reaction mixture was stirred at the room temperature for $5 \mathrm{~h}$. The inorganic components were removed by filtration and the excess of oxirane was removed by distillation under reduced pressure. The crude product was purified by silica gel column chromatography using hexane/ethyl acetate $(1: 1, \mathrm{v} / \mathrm{v})$ as an eluent. The product was obtained as pale yellow crystals ( $1.1 \mathrm{~g}, 75.3 \%$ yield) $\mathrm{mp}: 228-229^{\circ} \mathrm{C} . \mathrm{FW}=529.24 \mathrm{~g} \mathrm{~mol}^{-1}$. MS $\left(\mathrm{APCI}^{+}, 20 \mathrm{~V}\right)$, $\mathrm{m} / \mathrm{z}=530[\mathrm{M}+\mathrm{H}]^{+}, 358$. IR (in KBr) $v \mathrm{~cm}^{-1}: 3048\left(\mathrm{CH}_{\mathrm{ar}}\right), 2870$ $\left(\mathrm{CH}_{\text {aliphatic }}\right), 1479,1464\left(\mathrm{C}=\mathrm{C}_{\mathrm{ar}}\right), 1333(\mathrm{C}-\mathrm{N}), 1225(\mathrm{C}-\mathrm{O}-\mathrm{C})$; $\gamma \mathrm{cm}^{-1}: 740\left(\mathrm{CH}_{\mathrm{ar}}\right) .{ }^{1} \mathrm{H}$ NMR (300 MHz, DMSO- $\left.d_{6}\right), \delta(\mathrm{ppm})$ : $2.46\left(\mathrm{dd}, 3 H\right.$, in oxirane ring $\left.\left(H_{\mathrm{B}}\right), J_{\mathrm{BX}}=5.85 \mathrm{~Hz}\right), 2.72(\mathrm{dd}, 3 H$, in oxirane ring $\left.\left(H_{\mathrm{A}}\right), J_{\mathrm{AX}}=2.56 \mathrm{~Hz}, J_{\mathrm{AB}}=5.12 \mathrm{~Hz}\right), 3.21(\mathrm{~m}$, $3 H, \mathrm{CHO}), 4.12\left(\mathrm{dd}, 3 H\right.$, in $\left.-\mathrm{OCH}_{2}\left(H_{\mathrm{B}}\right), J_{\mathrm{BX}}=4.76 \mathrm{~Hz}\right), 4.49$ (dd, $3 H$, in $\left.-\mathrm{OCH}_{2}\left(H_{\mathrm{A}}\right), J_{\mathrm{AX}}=2.56 \mathrm{~Hz}, J_{\mathrm{AB}}=15.01 \mathrm{~Hz}\right), 6.09$ (s, $1 H, \mathrm{CH}), 6.93\left(\mathrm{dd}, 3 H,{ }^{3} J_{\mathrm{HH}}=7.32,7.68 \mathrm{~Hz}, H-6\right), 7.02(\mathrm{~s}$, $3 H, H-2), 7.11\left(\mathrm{dd}, 3 H,{ }^{3} J_{\mathrm{HH}}=6.95,7.32 \mathrm{~Hz}, H-5\right), 7.45(\mathrm{~d}, 3 H$, $J=7.68 \mathrm{~Hz}, H-7), 7.49$ (d, $3 H, J=8.42 \mathrm{~Hz}, H-4)$. Anal. Calcd. for $\mathrm{C}_{34} \mathrm{H}_{31} \mathrm{~N}_{3} \mathrm{O}_{3}$ : C, 77.10; H, 5.90; N, 7.93; O, 9.06. Found: C, $77.14 ; \mathrm{H}, 5.95 ; \mathrm{N}, 7.96 ; \mathrm{O}, 8.95$.

Tri(1-((3-methyloxetan-3-yl)methyl)- $1 H$-indol-3-yl)methane (5) was synthesized from $1 \mathrm{~g}(2.76 \mathrm{mmol})$ of $\operatorname{tri}\left(1 H_{-}\right.$ indol-3-yl)methane (1) by the same procedure like compound 
4. The crude product was purified by silica gel column chromatography (eluent hexane/ethylacetate $(1: 1, \mathrm{v} / \mathrm{v}))$. The product was obtained as pale yellow crystals $(1.25 \mathrm{~g}, 73.9 \%$ yield) $\mathrm{mp}: 233-234{ }^{\circ} \mathrm{C} . \mathrm{FW}=613.33 \mathrm{~g} \mathrm{~mol}^{-1}$. $\mathrm{MS}\left(\mathrm{APCI}^{+}\right.$, $20 \mathrm{~V}$ ), $m / z=614[\mathrm{M}+\mathrm{H}]^{+}$, 414. IR (in $\mathrm{KBr}$ ) $v \mathrm{~cm}^{-1}: 3050$ $\left(\mathrm{CH}_{\mathrm{ar}}\right), 2963,2870\left(\mathrm{CH}_{\text {aliphatic }}\right), 1466\left(\mathrm{C}=\mathrm{C}_{\mathrm{ar}}\right), 1361(\mathrm{C}-\mathrm{N})$, $1192(\mathrm{C}-\mathrm{O}-\mathrm{C}) ; \gamma \mathrm{cm}^{-1}: 735\left(\mathrm{CH}_{\mathrm{ar}}\right) .{ }^{1} \mathrm{H}$ NMR $(300 \mathrm{MHz}$, $\left.\mathrm{CDCl}_{3}\right) 1.23$ (s, $\left.9 H,-\mathrm{CH}_{3}\right), 4.21\left(\mathrm{~s}, 6 \mathrm{H}, \mathrm{N}-\mathrm{CH}_{2}\right), 4.29$ (d, $6 \mathrm{H}$, $\left.J=5.85 \mathrm{~Hz},-\mathrm{CH}_{2}\right), 4.56\left(\mathrm{~d}, 6 \mathrm{H}, J=6.22 \mathrm{~Hz},-\mathrm{CH}_{2}\right), 6.14(\mathrm{~s}$, $1 H, \mathrm{CH}), 6.59$ (s, $3 H, H-2), 7.03-6.97$ (m, 3H, H-6), 7.24-7.18 $(\mathrm{m}, 3 H, H-5), 7.35(\mathrm{~d}, 3 H, J=8.42 \mathrm{~Hz}, H-7), 7.46(\mathrm{~d}, 3 H$, $J=8.05 \mathrm{~Hz}, \mathrm{H}$-4). Anal. Calcd. for $\mathrm{C}_{40} \mathrm{H}_{43} \mathrm{~N}_{3} \mathrm{O}_{3}: \mathrm{C}, 78.27 ; \mathrm{H}$, 7.06; N, 6.85; O, 7.82. Found: C, 78.25; H, 7.01; N, 6.87; O, 7.87.

Tri(1-(4-ethylphenyl)-1H-indol-3-yl)methane (6). Tri( $1 H$ indol-3-yl)methane (1) $3 \mathrm{~g}$ (8.30 mmol), 1-ethyl-4-iodobenzene $6.16 \mathrm{~g}(26.54 \mathrm{mmol})$, copper(I) iodide $0.04 \mathrm{~g}(0.21 \mathrm{mmol})$, trans1,2-diaminocyclohexane $0.28 \mathrm{~g}(2.45 \mathrm{mmol})$ and potassium carbonate $8.59 \mathrm{~g}(62.24 \mathrm{mmol})$ were heated while stirring under reflux for $24 \mathrm{~h}$ in the mixture of $5 \mathrm{ml}$ of dry toluene and $8 \mathrm{ml}$ of dry 1,4-dioxane under $\mathrm{N}_{2}$ atmosphere. The reaction mixture was cooled down to ambient temperature. The inorganic components were removed by filtration. The solvents were removed by distillation under reduced pressure. The crude product was purified by silica gel column chromatography using hexane/chloroform $(5: 1, \mathrm{v} / \mathrm{v})$ as an eluent. The product was obtained as pale brownish crystals $(4.5 \mathrm{~g}, 80.3 \%$ yield) $\mathrm{mp}: 245-246^{\circ} \mathrm{C} . \mathrm{FW}=673.35 \mathrm{~g} \mathrm{~mol}^{-1} . \mathrm{MS}\left(\mathrm{APCI}^{+}, 20 \mathrm{~V}\right)$, $m / z=674[\mathrm{M}+\mathrm{H}]^{+}, 454$. IR (in KBr) $v \mathrm{~cm}^{-1}: 3048\left(\mathrm{CH}_{\mathrm{ar}}\right), 2962$ $\left(\mathrm{CH}_{\text {aliphatic }}\right), 1517,1461\left(\mathrm{C}=\mathrm{C}_{\mathrm{ar}}\right), 1215(\mathrm{C}-\mathrm{N}) ; \gamma \mathrm{cm}^{-1}: 739$ $\left(\mathrm{CH}_{\mathrm{ar}}\right) .{ }^{1} \mathrm{H}$ NMR $\left(300 \mathrm{MHz}, \mathrm{CDCl}_{3}\right) 1.30(\mathrm{t}, 9 \mathrm{H}, J=7.68 \mathrm{~Hz}$, $\left.{ }_{-} \mathrm{CH}_{3}\right), 2.72\left(\mathrm{~m}, 6 \mathrm{H},-\mathrm{CH}_{2}-\right), 6.36(\mathrm{~s}, 1 \mathrm{H}, \mathrm{CH}), 7.10$ (s, $3 \mathrm{H}, \mathrm{H}-$ 2), 7.15-7.26 (m, 3H, H-6), 7.27-7.22 (m, 3H, H-5), 7.31-7.29 (m, 6H, Ar), 7.40-7.37 (m, 6** $H, \mathrm{Ar}), 7.61(\mathrm{~d}, 3 H, J=8.42 \mathrm{~Hz}$, $H-7), 7.69(\mathrm{~d}, 3 H, J=8.05 \mathrm{~Hz}, H-4)$. Anal. Calcd. for $\mathrm{C}_{49} \mathrm{H}_{43} \mathrm{~N}_{3}$ : C, 87.33; H, 6.43; N, 6.24. Found: C, 87.29; H, 6.45; N, 6.26 .

\subsection{Instrumentation}

${ }^{1} \mathrm{H}$ NMR spectra of the solutions of the synthesized compounds in deuterated solvents were taken on a Varian Unity Inova $\left(300 \mathrm{MHz}\left({ }^{1} \mathrm{H}\right)\right)$ spectrometer. All the data are given as chemical shifts $\delta$ (ppm) downfield from $\mathrm{Si}\left(\mathrm{CH}_{3}\right)_{4}$. IR spectra were recorded using PerkinElmer FTIR System. The spectra of the solid compounds were performed in a form of $\mathrm{KBr}$ pellets. Electron impact mass spectra were obtained on Waters $2 \mathrm{Q}$ 2000.

UV absorption spectra were recorded at the room temperature using Spectronic Genesys ${ }^{\mathrm{TM}} 8 \mathrm{UV}$-vis spectrometer. Fluorescence spectra were measured at the ambient temperature using a HORIBA Jobin Yvon FluoroMax ${ }^{\circledR}-3$ spectrofluorometer. Phosphorescence spectra of compounds were measured at $77 \mathrm{~K}$ using a $15 \mathrm{~ms}$ delay time between the excitation with a microsecond flash lamp and the measurement. Differential scanning calorimetry (DSC) measurements were carried out with a PerkinElmer DSC-7 at $10^{\circ} \mathrm{C} \mathrm{min}^{-1}$ heating rate under nitrogen atmosphere.
The glass transition temperatures $\left(T_{\mathrm{g}}\right)$ were determined from the second heating scans. Thermogravimetric analysis (TGA) was performed on a Mettler Toledo TGA/SDTA852 ${ }^{\mathrm{e}}$ at a $10{ }^{\circ} \mathrm{C} \mathrm{min}^{-1}$ heating rate under nitrogen atmosphere. Melting points were measured on a Buchi 510 melting point apparatus.

The ionization potentials $\left(I_{\mathrm{p}}\right)$ of the films of the synthesized compounds were measured by electron photoemission in air method as described before [14]. The samples for the ionization potential measurements were prepared by dissolving compounds in tetrahydrofuran and casting thin layers on $\mathrm{Al}$ plates, pre-coated with ca. $0.5-\mu \mathrm{m}$ thick adhesive layer of the copolymer of methacrylic acid and nethacrylic acid (MKM). The function of this layer was not only to improve the adhesion but also to eliminate electron photoemission from $\mathrm{Al}$. No photoemission was detected from Al plate overcoated with MKM at illumination with up to $6.25 \mathrm{eV}$ quanta energy light. In addition, the MKM layer is conductive enough to avoid charge accumulation on it during measurements. The samples were illuminated with monochromatic light from the quartz monochromator with deuterium lamp. The power of the incident light beam was $(2-5) \times 10^{-8} \mathrm{~W}$. The negative voltage of $-300 \mathrm{~V}$ was supplied to the sample substrate. The counter-electrode with the $4.5 \mathrm{~mm} \times 15 \mathrm{~mm}$ slit for illumination was placed at $8 \mathrm{~mm}$ distance from the sample surface. The counter-electrode was connected to the input of the BK2-16 type electrometer, working in the open impute regime, for the photocurrent measurement. The $10^{-15}$ to $10^{-12} \mathrm{~A}$ strong photocurrent was flowing in the circuit under illumination.

\section{Results and discussion}

Tri(1H-indol-3-yl)methane (1) was synthesized by the tandem addition-elimination-(Michael) addition reaction from $1 \mathrm{H}$-indole and $1 \mathrm{H}$-indole-3-carbaldehyde in the presence of concentrated hydrochloric acid [13]. Compounds $\mathbf{2}-\mathbf{5}$ were obtained as described in Scheme 1 by alkylation of $\mathbf{1}$ with iodoethane, 1-iodobutane, 2-(chloromethyl)oxirane and 3-(bromomethyl)3-methyloxetane, respectively in the presence of a phase transfer catalyst (TBAS) and potassium hydroxide. Compound $\mathbf{6}$ was synthesized by Ullmann-Goldberg coupling of 1-ethyl-4-iodobenzene with tri( $1 H$-indol-3-yl)methane $\mathbf{1}$ in the presence of copper(I) iodide, potassium carbonate and trans1,2-cyclohexane as a ligand [15]. All these compounds were identified by IR absorption, ${ }^{1} \mathrm{H}$ NMR and mass spectrometries and elemental analysis. They are soluble in common organic solvents such as chloroform, dichloromethane, toluene and tetrahydrofuran.

The characteristic aromatic absorption at $3048-3050 \mathrm{~cm}^{-1}$ (C-H stretch), aliphatic absorption at $2962-2972 \mathrm{~cm}^{-1}$ (C-H stretches (compounds 2-6), at $1455-1466 \mathrm{~cm}^{-1}(\mathrm{C}=\mathrm{C}$ stretches) and absorption at $1333-1361 \mathrm{~cm}^{-1}$ due to $\mathrm{C}-\mathrm{N}$ stretching are clearly observed in the IR spectra of all tri $(1 H$-indol-3yl)methane-based compounds. The characteristic $\mathrm{C}-\mathrm{O}-\mathrm{C}$ bands at 1225 and $1192 \mathrm{~cm}^{-1}$ are observed in the IR spectra of $\mathbf{4}$ and $\mathbf{5}$, respectively. 


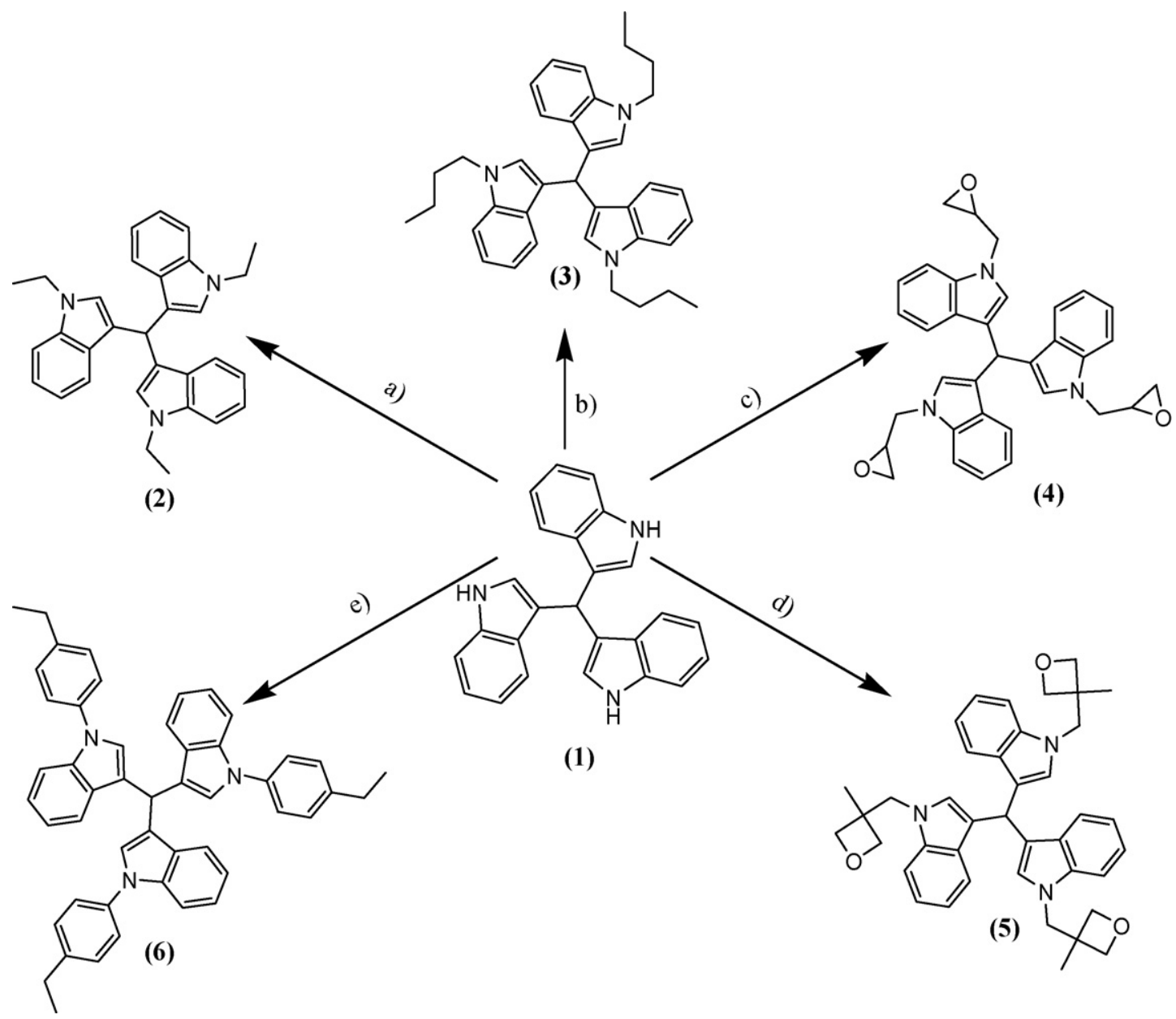

Scheme 1. (a) $\mathrm{C}_{2} \mathrm{H}_{5} \mathrm{I}, \mathrm{KOH},\left[\mathrm{Bu}_{4} \mathrm{~N}\right] \mathrm{HSO}_{4}$, acetone, $T=60^{\circ} \mathrm{C}$; (b) $\mathrm{C}_{4} \mathrm{H}_{9} \mathrm{I}, \mathrm{KOH},\left[\mathrm{Bu}_{4} \mathrm{~N}\right] \mathrm{HSO}_{4}$, acetone, $T=60^{\circ} \mathrm{C}$; (c) 2-(chloromethyl)oxirane, $\mathrm{KOH}$, $\mathrm{Na}_{2} \mathrm{SO}_{4}$, $T=25^{\circ} \mathrm{C}$; (d) 3-(bromomethyl)-3-methyloxetane, $\mathrm{KOH},\left[\mathrm{Bu}_{4} \mathrm{~N}\right] \mathrm{HSO}_{4}$, butan-2-one, $T=25^{\circ} \mathrm{C}$; (e) 1-ethyl-4-iodobenzene, CuI, trans-1,2-diaminocyclohexane, $\mathrm{K}_{2} \mathrm{CO}_{3}$, toluene, 1,4-dioxane, $115^{\circ} \mathrm{C}$.

The signals in ${ }^{1} \mathrm{HNMR}$ spectra of the synthesized compounds can be assigned to the characteristic aromatic and aliphatic hydrogen atoms. The proton signals at $6.09-6.36 \mathrm{ppm}$ can be assigned to the protons of central $\mathrm{CH}$ group of compounds 1-6.

The thermal properties of the synthesized hosts were examined by DSC and TGA under a nitrogen atmosphere. The values of glass transition temperatures, crystallization temperatures $\left(T_{\mathrm{cr}}\right)$, melting points $\left(T_{\mathrm{m}}\right)$ and $5 \%$ weight loss temperatures $\left(T_{\mathrm{ID}}\right)$ are summarized in Table 1. Alkyl substituted derivatives $\mathbf{2}$ and 3 exhibit lower thermal stability than oxiranyl, oxetanyl and

Table 1

Thermal characteristics of compounds 2-6

\begin{tabular}{lclll}
\hline Compound & $T_{\mathrm{g}}\left({ }^{\circ} \mathrm{C}\right)$ & $T_{\mathrm{m}}{ }^{\mathrm{a}}\left({ }^{\circ} \mathrm{C}\right)$ & $T_{\mathrm{cr}}{ }^{\mathrm{b}}\left({ }^{\circ} \mathrm{C}\right)$ & $T_{\mathrm{ID}}{ }^{\mathrm{c}}\left({ }^{\circ} \mathrm{C}\right)$ \\
\hline $\mathbf{2}$ & 123 & 230 & 173 & 245 \\
$\mathbf{3}$ & 104 & 214 & 169 & 262 \\
$\mathbf{4}$ & 75 & 233 & 115 & 306 \\
$\mathbf{5}$ & 98 & 243 & 175 & 284 \\
$\mathbf{6}$ & - & 257 & 170 & 310
\end{tabular}

a Determined from the second DSC heating scan.

${ }^{b}$ Determined from the second DSC heating scan.

c Temperature at which initial (5\%) loss of mass was observed. aryl substituted derivatives 4-6. Arylated derivative of tri $(1 H$ indol-3-yl)methane $\mathbf{6}$ demonstrates the highest thermal stability among the synthesized triindolylmethane-based compounds.

Compounds 2-6 were obtained as crystalline materials, however all of them except compound $\mathbf{6}$ could be transformed into the glassy state with the relatively high glass transition temperatures ranging from 75 to $123^{\circ} \mathrm{C}$. Fig. 1 shows DSC curves of compound $\mathbf{5}$. Compound $\mathbf{5}$ obtained as a crystalline material in the first DSC heating scan showed only endothermic melting signal at $243^{\circ} \mathrm{C}$. After the slow recooling the second heating scan revealed glass transition at $98^{\circ} \mathrm{C}$, exothermic crystallization signal at $175^{\circ} \mathrm{C}$ and again melting signal. Thus it can be regarded as molecular glass. All the synthesized compounds show crystallization signals in the second heating scan. This observation can be explained by the regular structure of triindolylmethanes, influenced by $\mathrm{sp}^{3}$ hybridized carbon $(\mathrm{CH}$ group). The glass transitions were recorded for all the materials except 6.

The synthesized compounds were studied by UV-vis and luminescence spectrometries. The absorption spectra of compounds 2-5 are similar due to the presence of the same chromophore. They exhibit absorption band in the range of 243-325 nm due to $\pi \rightarrow \pi^{*}$ electronic transitions. The spectrum 


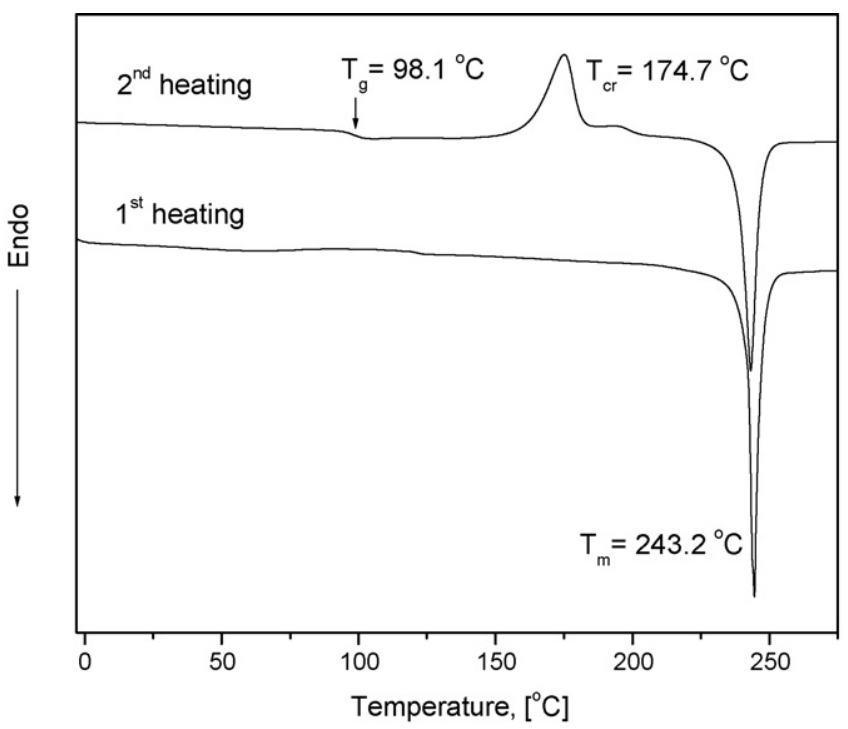

Fig. 1. DSC curves of compound 5 at the heating rate of $10^{\circ} \mathrm{C} \mathrm{min}^{-1}$ in nitrogen atmosphere.

Table 2

Room temperature UV absorption spectrometry data for dilute THF solutions $\left(\times 10^{-5} \mathrm{M}\right)$ of compounds 2-6 and 1-(oxiran-2-ylmethyl)- $1 H$-indole (EPI)

\begin{tabular}{lrll}
\hline Compound & $\lambda_{\max }(\mathrm{nm})$ & $\begin{array}{l}\varepsilon_{\max } \\
\left(\times 10^{-4} \mathrm{~mol}^{-1} \mathrm{dm}^{3} \mathrm{~cm}^{-1}\right)\end{array}$ & $\begin{array}{l}\text { Bathochromic } \\
\mathrm{shift}^{\mathrm{a}}(\mathrm{nm})\end{array}$ \\
\hline $\mathbf{2}$ & 293 & 1.91 & 18 \\
$\mathbf{3}$ & 291 & 1.35 & 16 \\
$\mathbf{4}$ & 290 & 1.16 & 15 \\
$\mathbf{5}$ & 294 & 2.60 & 19 \\
$\mathbf{6}$ & 262,301 & $5.43,3.28$ & 26 \\
EPI & 275 & 0.62 & - \\
\hline
\end{tabular}

${ }^{\text {a }}$ With respect to EPI.

of compound $\mathbf{6}$ has additional high-energy absorption band due to the presence of 4-ethylphenyl group. The data pertinent to the absorption maxima of triindolylmethane-based compounds are given in Table 2. For the comparison, the corresponding data for 1-(oxiran-2-ylmethyl)-1H-indole (EPI) [16] are presented. The UV absorption bands of all the synthesized triiindolylmethanebased compounds show bathochromic shift with respect to the absorption band of EPI and the enhanced values of molar extinction coefficient $\left(\varepsilon_{\max }\right)$. The spectrum of compound $\mathbf{6}$ shows the highest values of $\varepsilon_{\max }$ and the most considerable bathochromic shift with respect to the spectrum of EPI. This is apparently the

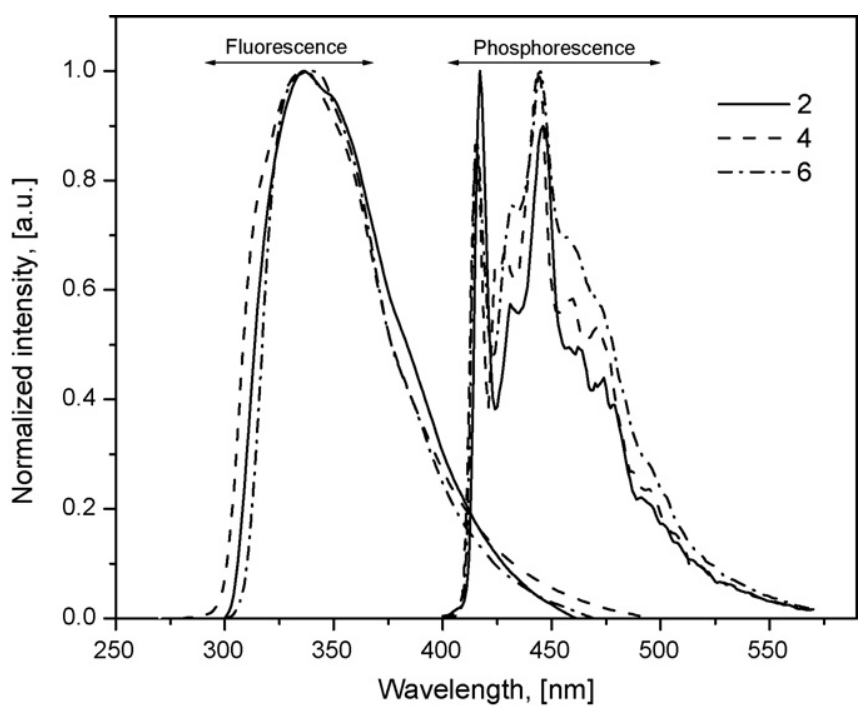

Fig. 2. Fluorescence (at the room temperature) and phosphorescence (at $77 \mathrm{~K}$ ) spectra of dilute toluene solutions $\left(\times 10^{-5} \mathrm{M}\right)$ of compounds $2, \mathbf{4}$ and $\mathbf{6}$. $\lambda_{\mathrm{ex}}=300 \mathrm{~nm}$.

consequence of the enlarged conjugated $\pi$-electron system of compound 6.

Fig. 2 shows the fluorescence and phosphorescence emission spectra of dilute toluene solutions of the selected compounds recorded at $77 \mathrm{~K}$ using the excitaion wavelength $\lambda_{\text {ex }}$ of $300 \mathrm{~nm}$. The pertinent data are summarized in Table 3. The fluorescence spectra of compounds $\mathbf{2 , 4}$ and $\mathbf{6}$ are very similar. No red shift of the spectrum of compound $\mathbf{6}$, which was characteristic of the UV spectrum, is observed. The phosphorescence spectra of compounds 2, $\mathbf{4}$ and $\mathbf{6}$ are also similar. The triplet energies $E_{\mathrm{T}}$ established from the highest energy phosphorescence peaks of the dilute solutions of these compounds are almost identical, i.e. $2.97-2.99 \mathrm{eV}$ (Table 3). These values of triplet energies are higher than those reported for the common triplet blue emitters used in electrophosphorescent devices iridium(III) bis[(4,6-difluorophenyl)pyridinato-N, $\left.\mathrm{C}^{2^{\prime}}\right]$ (FIrpic) $2.62 \mathrm{eV}$ and [(dfppy) $)_{2} \operatorname{Ir}$ (fpy)] (FIrfpy) $2.68 \mathrm{eV}[11]$.

Fig. 3 shows fluorescence and phosphorescence spectra of the spin-coated thin-film samples of compounds $\mathbf{2}, \mathbf{4}$ and $\mathbf{6}$. The data pertinent to the intensity maxima of these spectra are given in Table 3. Fluorescence spectra of the films are similar to those of dilute solutions. However phosphorescence intensity maxima of the films of $\mathbf{2}, \mathbf{4}$ and $\mathbf{6}$ exhibit considerable bathochromic shifts with respect to the corresponding max-

Table 3

Photophysical characteristics of compounds 2, 4 and 6

\begin{tabular}{lllllll}
\hline Compound & Solution & & \multicolumn{2}{l}{ Film } & $E_{\mathrm{T}}(\mathrm{eV})^{\mathrm{a}}$ & $E_{\mathrm{T}}(\mathrm{eV})^{\mathrm{b}}$ \\
\cline { 2 - 3 } & Fluorescence $\lambda_{\max }(\mathrm{nm})^{\mathrm{c}}$ & Phoshorescence $\lambda_{\max }(\mathrm{nm})^{\mathrm{c}}$ & & Fluorescence $\lambda_{\max }(\mathrm{nm})$ & Phoshorescence $\lambda_{\max }(\mathrm{nm})$ & 2.97 \\
$\mathbf{2}$ & 336 & 417,446 & 340 & 440,513 & 2.81 \\
$\mathbf{6}$ & 336 & 416,444 & 340 & 449,512 & 2.76 \\
$\mathbf{6}$ & 340 & 416,444 & 340 & 439,470 & 2.89 \\
\hline
\end{tabular}

\footnotetext{
a Triplet energy estimated from the highest energy phosphorescence peak in solution.

b Triplet energy estimated from the highest energy phosphorescence peak in spun film.

${ }^{\mathrm{c}}$ In toluene solutions $\left(\times 10^{-5} \mathrm{M}\right)$, phosphorescence at $77 \mathrm{~K}$.
} 


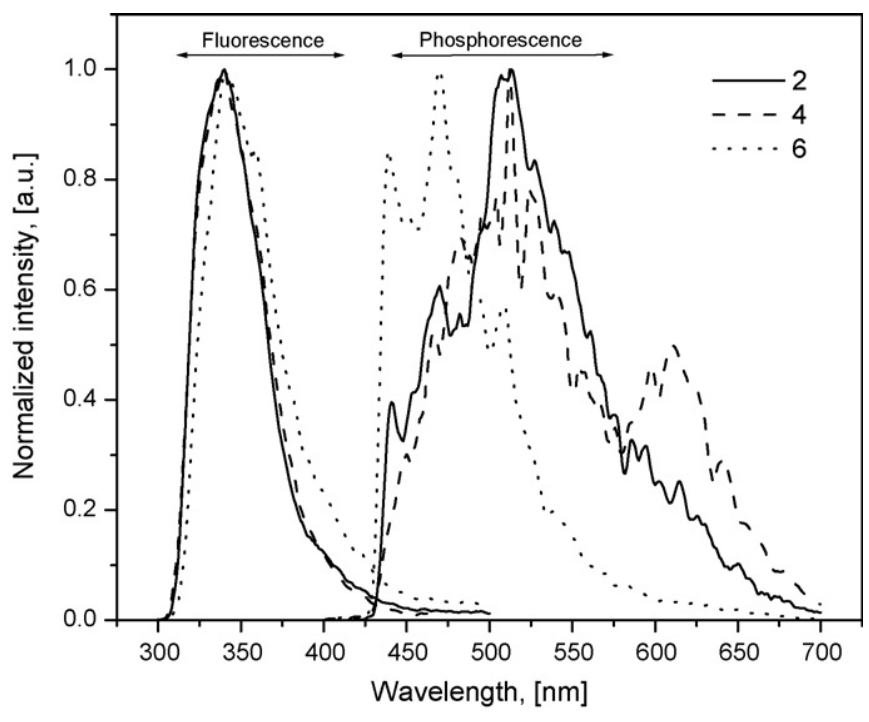

Fig. 3. Room temperature fluorescence and phosphorescence spectra of thin films of compounds $\mathbf{2}, \mathbf{4}$ and 6. $\lambda_{\mathrm{ex}}=270 \mathrm{~nm}$.

ima of the spectra of dilute solutions, as typically observed for various phosphorescent host materials [6]. For the highest energy phosphorescence peaks, which are used for the estimation of triplet energies, these shifts are from $23 \mathrm{~nm}$ for $\mathbf{2}$ and $\mathbf{6}$ to $33 \mathrm{~nm}$ for 4 . For the highest intensity phosphorescence peaks the bathochromic shifts are from $26 \mathrm{~nm}$ for 6 to $67 \mathrm{~nm}$ and $68 \mathrm{~nm}$ for 2 and 4, respectively. Thus in the films triplet emission occurs at lower energy. Apparently intermolecular interaction, e.g. formation of triplet excimers takes place in the solid samples of the synthesized triindolylmethane-based compounds. The smallest bathochromic shift was observed for the phosphorescence spectra of the solid sample of 6 . The presence of 4-ethylphenyl groups in these molecules apparently hinders the formation of excited dimers. The triplet energies established from the highest energy phosphorescence peaks of these compounds in the solid state are slightly lower than in dilute solutions (Table 3).

An important characteristic of electronically active compounds is ionization potential, which characterizes the electron releasing work under illumination. $I_{\mathrm{p}}$ values for the thin films of the synthesized compounds were established by electron photoemission technique from the dependencies of photocurrent $(I)$ on the incident light quanta energy, which are named as electron photoemission spectra and plotted as $I^{0.5}=f(h v)$. Fig. 4 shows electron photoemission spectra of the films of compounds 2-6. Electron photoemission spectrum of EPI is given for the comparison. The intersection points of the straight lines down with abscissa axis give the values of the ionization potentials. The values of $I_{\mathrm{p}}$ in $\mathrm{eV}$ are 5.72 for $\mathbf{2}, 5.78$ for $\mathbf{3}, 5.80$ for $\mathbf{4}$, 5.74 for 5 and 5.67 for $\mathbf{6}$ and $5.8 \mathrm{eV}$ for EPI. It is evident that replacing alkyl groups by aryl group shifts the ionization potential to lower energy. These data are consistent with UV and fluorescence data. Generally, the ionization potentials of the synthesized compounds are close to those of the derivatives of carbazole, 3,3'-bi(9H-carbazole) and fluorene used as host materials in the emission layers of electrophosphorescent devices [9].

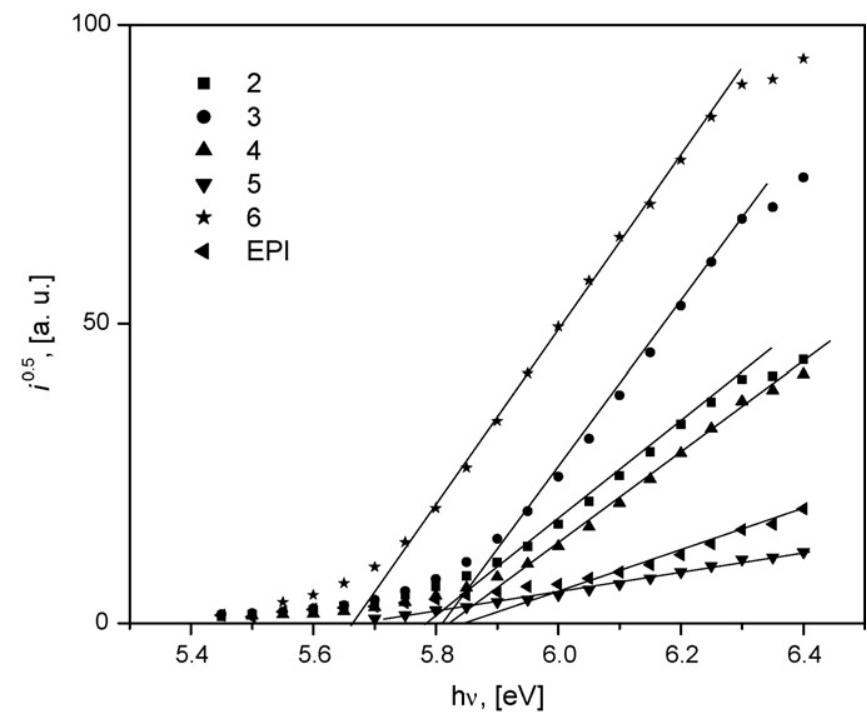

Fig. 4. Electron photoemission spectra in air of the films of compounds 2-6.

In conclusion, we have synthesized a series of new triiindolylmethane-containing compounds and have studied their thermal, optical, photophysical and photoelectrical properties. The synthesized compounds exhibit moderate thermal stability with $5 \%$ weight loss temperatures ranging from 245 to $310^{\circ} \mathrm{C}$ and form glasses with glass transition temperatures in the range of $98-123^{\circ} \mathrm{C}$. The ionization potentials of the synthesized materials measured by the electron photoemission in air technique range from 5.67 to $5.80 \mathrm{eV}$. The synthesized compounds show relatively high triplet energies in the range from 2.97 to $2.99 \mathrm{eV}$.

\section{Acknowledgments}

Financial support from the Lithuanian Science and Studies Foundation and from National Science Council of Taiwan is gratefully acknowledged. M.-H. Tsai also thanks the financial support from the Mediatek fellowship. Dr. Habil. V. Gaidelis is thanked for the help in ionization potential measurements.

\section{References}

[1] C.W. Tang, S.A. Van Sylke, Appl. Phys. Lett. 51 (1987) 913.

[2] S. Tokito, T. Iijima, Y. Suzuri, H. Kita, T. Tsuzuki, F. Sato, Appl. Phys. Lett. 83 (2003) 569.

[3] C. Adachi, M. Baldo, M.E. Thompson, S.R. Forrest, J. Appl. Phys. 90 (2001) 5048.

[4] M.-H. Tsai, Y.-H. Hong, C.-H. Chang, H.-C. Su, C.-C. Wu, A. Matoliukstyte, J. Simokaitiene, S. Grigalevicius, J.V. Grazulevicius, C.-P. Hsu, Adv. Mater. 19 (2007) 862.

[5] R.J. Holmes, S.R. Forrest, Y.-J. Tung, R.C. Kwong, J.J. Brown, S. Garon, M.E. Thompson, Appl. Phys. Lett. 82 (2003) 2422.

[6] Y.-C. Chen, G.-S. Huang, C.-C. Hsiao, S.-A. Chen, J. Am. Chem. Soc. 128 (2006) 8549.

[7] M.-H. Tsai, H.-W. Lin, H.-C. Su, T.-H. Ke, C.-C. Wu, Fu-C. Fang, Y.-L. Liao, K.-T. Wong, C.-I. Wu, Adv. Mater. 18 (2006) 1216.

[8] K. Brunner, A. Van Dijken, H. Börner, J. Am. Chem. Soc. 126 (2004) 6035.

[9] P.A. Vecchi, A.B. Padmaperuma, H. Qiao, L.S. Sapochak, P.E. Burrows, Org. Lett. 8 (2005) 4211. 
[10] P.-I. Shih, C.-H. Chien, C.-Y. Chuang, C.-F. Shu, C.-H. Yang, J.-H. Chen, Y. Chi, J. Mater. Chem. 17 (2007) 1692.

[11] A.B. Padmaperuma, L.S. Sapochak, P.E. Burrows, Chem. Mater. 18 (2006) 2389.

[12] D.R. Lidle, Handbook for Organic Solvents, CRC Press, Boca Raton, 1995.

[13] C. Bahner, T. Kinder, H. Gutman, J. Med. Chem. 8 (1965) 397.
[14] S. Grigalevicius, G. Blazys, J. Ostrauskaite, J.V. Grazulevicius, V. Gaidelis, V. Jankauskas, E. Montrimas, Synth. Met. 128 (2002) 127.

[15] J.C. Antilla, A. Klapars, S.L. Buchwald, J. Am. Chem. Soc. 124 (2002) 11684.

[16] J. Hartenstein, J. Schaechtele, C. Barth, Ger. Offen. 35 (1993) 26. 